\title{
AS DIFERENTES TERMINOLOGIAS DA TIRA CÔMICA NO LIVRO DIDÁTICO
}

\author{
The different terminologies of the comic strip in the textbook
}

\author{
Beatriz DEROZA \\ Universidade Federal de São Paulo \\ beatriz.deroza@gmail.com \\ Paulo Eduardo RAMOS \\ Universidade Federal de São Paulo \\ contatopauloramos@gmail.com
}

\begin{abstract}
RESUMO: As tiras cômicas ficaram conhecidas pelo formato tendencialmente curto, horizontal e retangular de seus quadrinhos, resultado de uma padronização adotada pelos jornais, que eram seu principal suporte de divulgação no século XX. Com a consolidação de novos suportes e das mídias sociais, esse formato mais regular passou a ser revisto e redimensionado. Desde que esse gênero dos quadrinhos foi inserido nos livros didáticos, alunos de escolas públicas e particulares têm tido contato com os diferentes moldes utilizados pelos autores das tiras cômicas. Paralelamente, tem sido comum perceber uma confusão na percepção do que seja tira, tirinha, charge e história em quadrinhos. Busca-se demonstrar, nesta comunicação, que essa imprecisão do livro didático, ao utilizar cada um desses termos, tende a causar desentendimento sobre o tema e problemas para desenvolver atividades práticas. O objeto de análise são tiras cômicas retiradas de um livro didático de língua portuguesa do $6^{\circ}$ ano do ensino fundamental II, da editora Uno, onde é possível encontrar trinta e sete tiras, trabalhadas junto aos alunos com diferentes terminologias. Como pressupostos teóricos para fundamentar esta análise, leva-se em conta a definição de tira cômica, abordagem no ensino e os formatos abrangentes estabelecidos por Ramos (2011, 2012, 2014b, 2017), além da definição de suporte de Bonini (2011). PALAVRAS-CHAVE: Tira cômica; Terminologia; Ensino.
\end{abstract}

\begin{abstract}
The comic strips became known for the short, horizontal and rectangular format of their comics, the result of a standardization adopted by newspapers, which were their main support for dissemination in the 20th century. Due to the consolidation of new media and social media, this regular format started to be revised and resized. Since this genre of comics was inserted in textbooks, students from public and private schools have had contact with the different molds used by the
\end{abstract}


authors of the comic strips. At the same time, it has been common to notice a confusion in the perception of what is a comic strip, comic strip, cartoon and story. The aim of this communication is to demonstrate that this inaccuracy of the textbook, when using each of these terms, tends to cause disagreement about the theme and problems to develop practical activities. The aim of analysis are comic strips taken from a textbook of Portuguese language of the 6th year of elementary school II, by Uno publisher, where it is possible to find thirty-seven strips, worked with students with different terminologies. As theoretical assumptions to support this analysis, the definition of comic strip, approach in teaching and the comprehensive formats established by Ramos $(2011,2012,2014 b, 2017)$ are considered, in addition to the definition of support by Bonini (2011). KEYWORDS: Comic strip; Terminology; Teaching.

\section{INTRODUÇÃO}

As tiras cômicas ou comic strips, no inglês, começaram a circular nos periódicos norte-americanos no fim do século XX e sempre chamaram a atenção dos leitores por seu formato próprio e diferenciado. Ao serem veiculadas em diversos jornais, as tiras e seus personagens tornaram-se populares mundialmente e, nos dias de hoje, é possível encontrá-las em coletâneas, livros ilustrados, pages no Facebook, blogs e livros didáticos. O formato curto, horizontal, geralmente com três ou quatro quadros tendia a ser o padrão das tiras, entretanto, ao serem veiculadas em outros suportes e mídias, seu formato engessado não era mais necessário e, com isso, houve uma flexibilização nos moldes dependendo do suporte em que é veiculada.

Nas mídias virtuais, por exemplo, podemos encontrar tiras duplas e triplas na vertical, já que esse formato facilita a leitura do usuário ao abrir seu feed de notícias. Nos vestibulares, devido ao formato da prova, é necessário remodelar tiras da horizontal para a vertical e dividi-las em dois blocos, quadrinhos na parte de cima e na parte debaixo para adequar-se ao padrão das demais questões da prova.

Desde que as tiras cômicas passaram a integrar os livros didáticos no Brasil, alunos de escolas públicas e particulares têm tido contato com esse gênero e suas marcas, sendo a principal delas o desfecho cômico. Paralelamente, tem sido comum perceber uma confusão na percepção do que seja tira, tirinha, charge e história em quadrinhos, justamente pelas características em comum como: o uso de balões e quadrinhos, multimodalidade (texto + imagem) e histórias em narrativas. Ao abordar esses gêneros no âmbito escolar, é de grande importância que o professor esteja familiarizado com as marcas centrais de 
cada um para orientar seus alunos nas atividades práticas em sala de aula. Entretanto, neste estudo, podemos notar a falta de familiaridade do profissional que desencadeia uma confusão entre os gêneros e equívocos por parte dos alunos ao realizarem as atividades.

Torna-se importante destacar, que neste estudo a formação do professor não está em questão. Nosso objetivo é analisar as diferentes nomenclaturas e formatos adotados pelo livro didático, que podem estar na base das prováveis causas para as imprecisões dos alunos na produção de suas próprias tiras cômicas. Para isso, a análise baseou-se no livro de Língua Portuguesa do $6^{\circ}$ ano do ensino fundamental II, da editora Uno, escrito por Rosilene dos Anjos e Rosane Pamplona.

\section{FORMATO E SUPORTE}

Segundo Vergueiro (2017), quando as tiras cômicas tinham o jornal impresso como seu único suporte, durante o século XX no Brasil e nos Estados Unidos, um formato fixo foi estabelecido pelos editores, já que, a visão mercadológica estava em primeiro plano e a lógica era bem simples: devido ao seu grande sucesso, as tiras aumentavam as vendas dos jornais que recebiam uma grande quantidade de produções enviadas por autores interessados em vendê-las. Para os editores, era mais vantajoso colocar um número maior de tiras (de diferentes autores) na página diária de quadrinhos do que colocar tiras de um único quadrinista. Assim, o jornal despertava o interesse do público-alvo, aumentava o número de vendas e mais quadrinistas tinham a oportunidade de publicar suas produções e faturar com isso.

Para que toda essa lógica funcionasse, os editores padronizaram o formato mais adequado, devido à diagramação da página do jornal, sendo ele curto, horizontal e com três ou quatro quadros. Apenas nos periódicos dominicais, os autores publicavam tiras fora desse padrão. Alguns quadrinistas não eram totalmente a favor desse formato único. Um deles é Bill Watterson, autor das tiras de Calvin e Haroldo. No livro do "Décimo aniversário" ele critica essa imposição dos periódicos. Segundo ele, "ao impor formatos reduzidos e padronizados a todas as tiras, os jornais obrigaram os quadrinistas a se pautar pelo custo benefício, e não pelas possibilidades visuais que a página de quadrinhos poderia oferecer" (WATTERSON, 1995, p. 8).

Com o passar dos anos, o desejo de Watterson foi "atendido" e outros suportes começaram a veicular as tiras cômicas, dentre eles o livro didático, que é o corpus dessa pesquisa. Para transferir a tira de suporte, é comum que modificações no formato sejam feitas e, neste ponto, começam os questionamentos sobre este gênero. Ao mudarmos a 
tira de um suporte para o outro, isso afeta seu o conteúdo? É possível que a mudança de suporte altere o gênero tira cômica? Ramos (2015, p. 782) afirma que "as marcas centrais do gênero tira cômica são mantidas nos novos suportes. Sob esse aspecto, não há mudança de gênero". Para exemplificar a razão pela qual consentimos com a afirmação de Ramos, destacamos dois exemplos de uma mesma tira de Calvin e Haroldo veiculada em suportes diferentes:

Figura 1
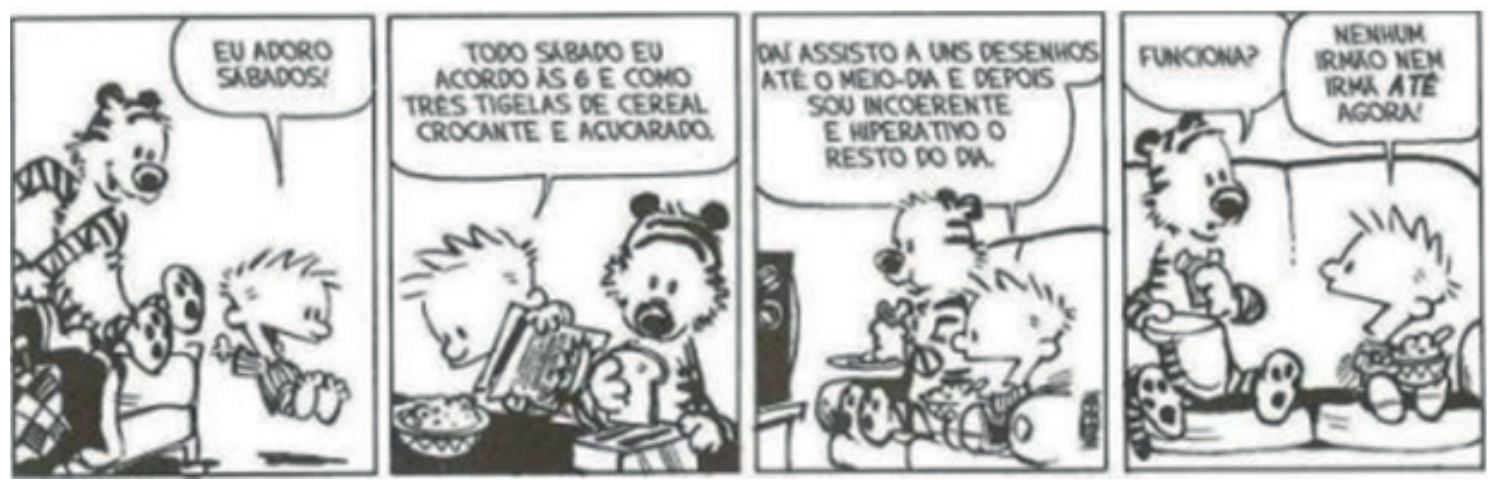

Fonte: ANJOS; PAMPLONA, 2016. 
10. Examine a história em quadrinhos Cakvin e Haroldo para responder a prósima questio.
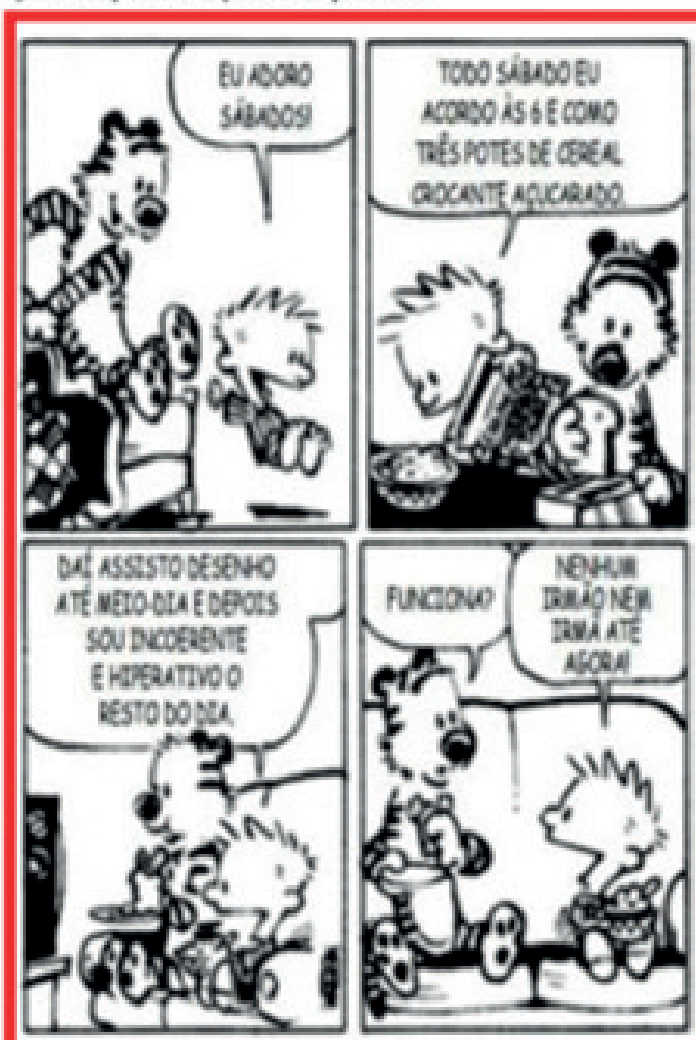

(awe kidmapasecen. Alagtade)

A lekura da tra permite conciur que

(A) a persenagem disple de centos comportamertes para evitar a chegada de irmalos.

(B) comer cereal crocarthe açucarado et uma forma de se marter incoerente.

(C) ser hiperativo acs sabados 6 uma maneira de afastar o estresse da semana.

(D) a personagem esta decepeionada por nas ser nertim imbo nem iml.

(E) ver abuns desenhos na tekvisto ajuda a conservar os lapes de amizade.

\section{GABARITO}

\begin{tabular}{|c|c|c|c|}
\hline $\begin{array}{rr}1-\mathrm{B} & 3-\mathrm{C} \\
2-\mathrm{A} & 4-\mathrm{D}\end{array}$ & $\begin{array}{l}\text { 5. C } \\
\text { 6. B }\end{array}$ & $\begin{array}{l}\text { 7. } 0 \\
\text { B. E }\end{array}$ & $\begin{array}{l}\text { 9- E } \\
\text { 10- A }\end{array}$ \\
\hline
\end{tabular}

\section{Prova de Redação}

Com a crise economica nacional. mulas acbes e projetos sociais precisam ser adctados. Cada governo imuricipal. estadual ou federal deve pricrizar esses projetos e apbes de formas distintas.

Consiberando a charge abaik apresentada, elaboce um texto dissertativo-argumentativo sobre o tema: Os projetos e as açes sociais que o Brasil deve priorizar nessa crise.

Ao desenvolver o tema proposto, procure usar os conhecimentos adquiridos e as refexobes feltas ao bengo de sua formactso. Selecione, organize e relacione argumentos, tatos e opinibes para defender seu ponto de vista e suas propostas, sem ferr os direibos humanos.

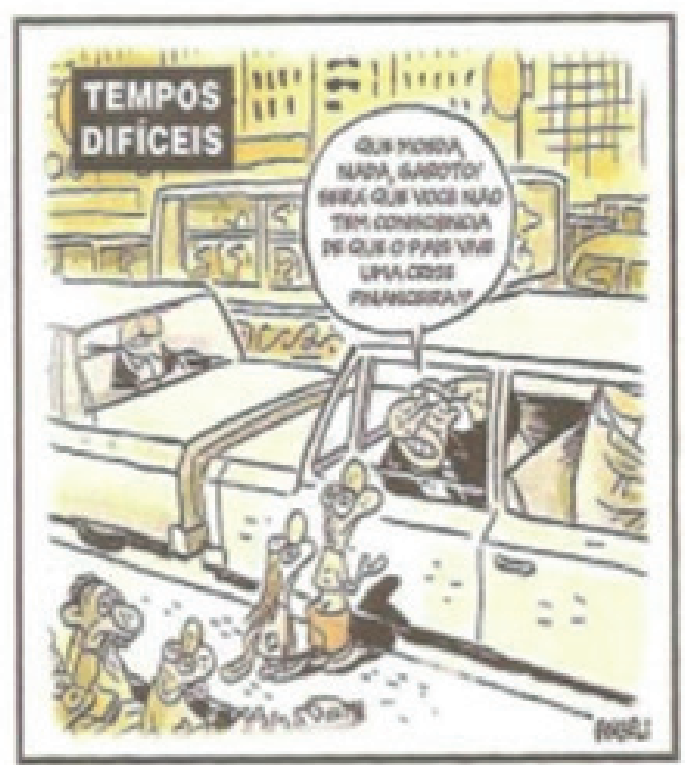

Instruçces:

- Seu texdo lem de ser escrito a tinta. na follha propria.

- Desenvolva seu texbo em prosa: nalo redia narraclo, nem poema.

- O texto com ate 7 (sete) Inhas escritas sera considerado texdo em branco.

- O texeo deve ter, no masimo, 20 linhas.

- O Rascunho da redaçbo deve ser feto no espaço aprogriedo.

Simulado de Português e Redaçăo

www.eversonportugues.com

Fonte: Simulado de Língua Portuguesa.

Disponível em: $<$ https://www.eversonportugues.com>. Acesso em: 30 jan. 2020. 
Após a leitura das duas tiras, podemos notar que o conteúdo verbal e visual é o mesmo, a única mudança foi na disposição dos quadros. Na primeira, temos o formato padronizado, pois inicialmente foi veiculada no jornal; na segunda, temos um formato com duas colunas na vertical, porém com o mesmo número de quadros da primeira, apenas estão em uma disposição diferente, ou seja, foram adaptados para o novo suporte mantendo as características do gênero, sendo a principal delas o desfecho cômico. Caso haja mudanças no conteúdo da tira, isso pode configurar um novo gênero ou não, tudo depende de como as modificações alteraram o entendimento da tira, portanto cada caso precisa ser analisado cautelosamente.

Segundo Bonini (2011), suporte é "um elemento material (de registro, armazenamento e transmissão de informação) que intervém na concretização dos três aspectos caracterizadores de uma mídia (suas formas de organização, produção e recepção)"'. Assim, ao falarmos do suporte livro didático, temos um material de transmissão de informação que não necessariamente modifica o gênero tira cômica, contudo, não podemos afirmar que é do conhecimento do professor e dos alunos que essas modificações no formato da tira para determinados suportes não alteram suas principais características.

O livro didático selecionado enquanto objeto de estudo, após algumas análises, foi o que apresentou maior número de tiras cômicas nomeadas de maneira ambígua. Para esta análise, escolhemos exemplos das variações de formato das tiras, todavia, ao colocar esses exemplos, eles contradizem a definição pré-estabelecida e podem causar confusão para os alunos e talvez nos professores também. Segundo Rama e Vergueiro (2004), "na utilização de quadrinhos no ensino, é muito importante que o professor tenha suficiente familiaridade com o meio, conhecendo os principais elementos da sua linguagem e os recursos que ela dispõe para representação do imaginário". Partindo do pressuposto de que a formação do professor não o prepara para lidar com essa variedade de característica do gênero, muitas vezes essa função recai para o livro didático. Porém, o que podemos notar no livro analisado é uma definição de tira cômica que não abarca todas as dimensões desse gênero e que acaba aproximando-o de outros gêneros que também fazem parte do hipergênero dos quadrinhos.

\section{TERMINOLOGIAS}

Desde que as tiras cômicas vieram para o Brasil, uma grande pluralidade de nomenclaturas foi surgindo a partir da tradução do inglês de comic strips. As mais comuns são: tira, tira cômica, tira em quadrinhos, tira jornalística, tirinha, entre outras. Segundo 
Ramos (2017), "a pluralidade de formas para se referir às tiras ajuda a nublar a forma como devam ser nomeadas. Daí se abre o caminho para a diversidade de possibilidades". É neste caminho "nublado" que o livro da editora Uno está. O material começa definindo tira cômica como "uma história em quadrinhos, geralmente com três ou quatro quadros, veiculada em jornais e revistas em uma única faixa horizontal" (ANJOS; PAMPLONA, 2016, p. 4) porém, após a leitura dos enunciados, encontramos mais duas nomenclaturas diferentes à da definição, mas que também se referem as tiras. Em resumo: trinta e sete tiras cômicas foram utilizadas em exercícios, mas com três nomenclaturas diferentes, nos enunciados do livro de Língua Portuguesa do $1^{\circ}$ ao $4^{\circ}$ bimestre. Vejamos no gráfico a seguir:

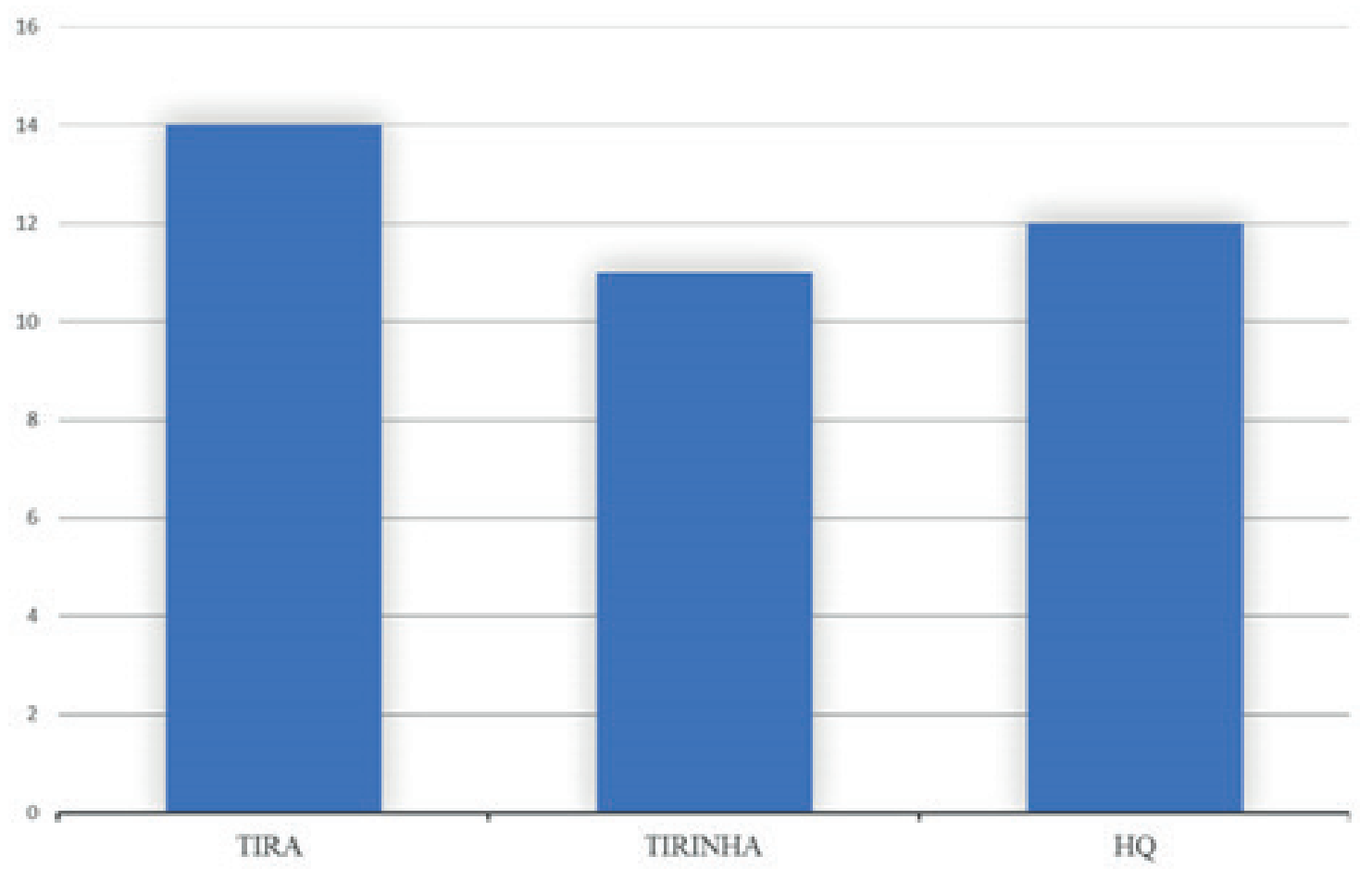

Fonte: ANJOS; PAMPLONA, 2016.

Em uma primeira leitura, essa pluralidade de nomes pode não causar tantas implicações, no entanto, ao relacionar a nomenclatura com o formato em que a imagem aparece no enunciado, as ambiguidades sobressaem. Vejamos o exemplo a seguir de duas tiras cômicas do quadrinista Jim Davis, criador das tiras de Garfield, que estão no formato padronizado (horizontal, com três ou quatro quadros) e que foram nomeadas de maneiras diferentes pelo livro didático: 
Figura 3

\section{Leia esta tira.}

GARFIELD
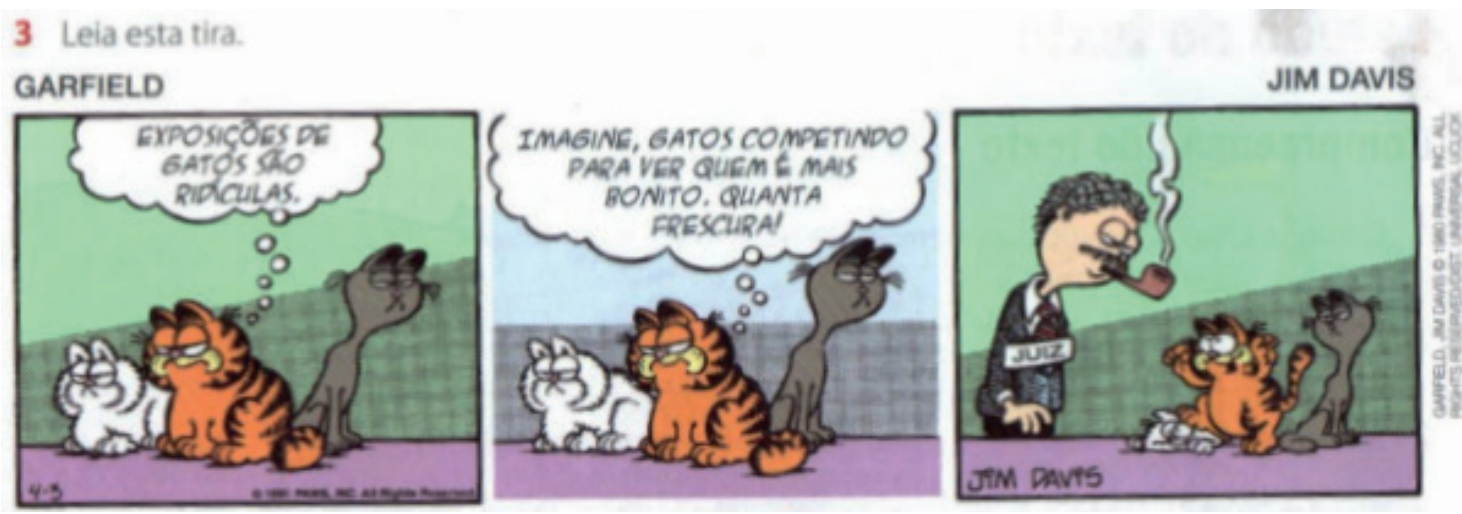

Fonte: ANJOS; PAMPLONA, 2016.

Figura 4

4 Observe estes quadrinhos.

GARFIELD
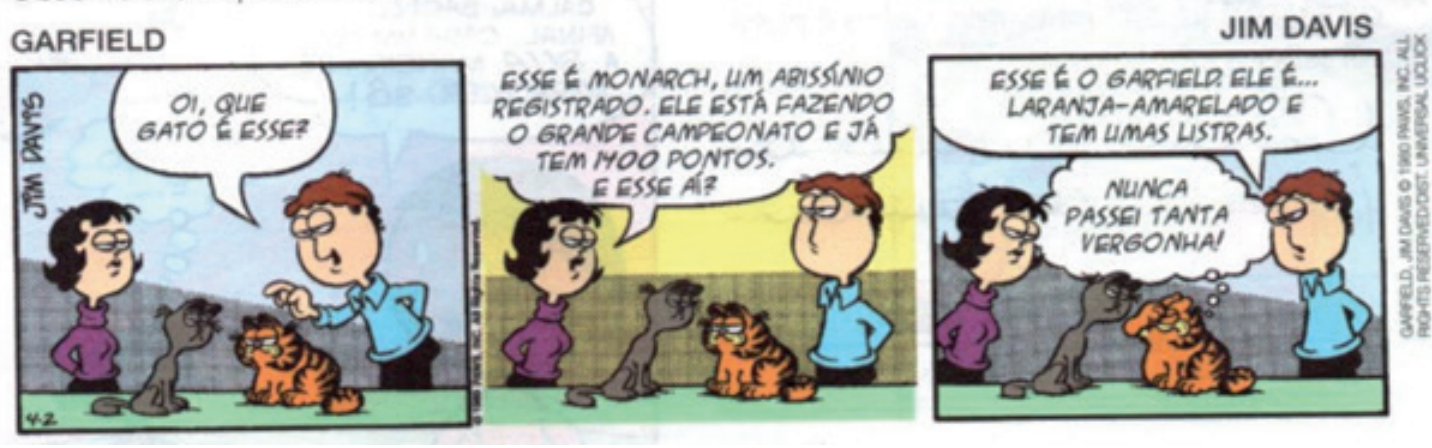

Fonte: ANJOS; PAMPLONA, 2016.

Já nas primeiras páginas do livro (exercícios 3 e 4), os alunos encontram duas nomenclaturas diferentes para denominar tiras com formatos idênticos. Vale a pena ressaltar novamente que, para alunos e professores que não estão habituadas a lidar com essa ambiguidade de terminologias, pode parecer que a primeira é uma tira e a segunda não, mas as duas são. Entende-se que o material didático deva orientar professores e alunos a desenvolverem uma leitura crítica sobre as tiras, não apenas fazer uma leitura superficial com o foco apenas no conteúdo gramatical, por exemplo. Segundo Vergueiro e Santos (2012) “é importante lembrar que a leitura de quadrinhos é complexa e não deve se restringir ao texto ou ao enredo; ler é perceber os recursos da linguagem, da estética e das narrativas quadrinizadas". O livro da editora Uno, na maioria dos exercícios, faz uso das 
tiras cômicas apenas como um mero recurso ilustrativo para introduzir um novo conteúdo gramatical ou algo que auxilie na produção de texto. Vejamos o exemplo

2 Leia esta tira.

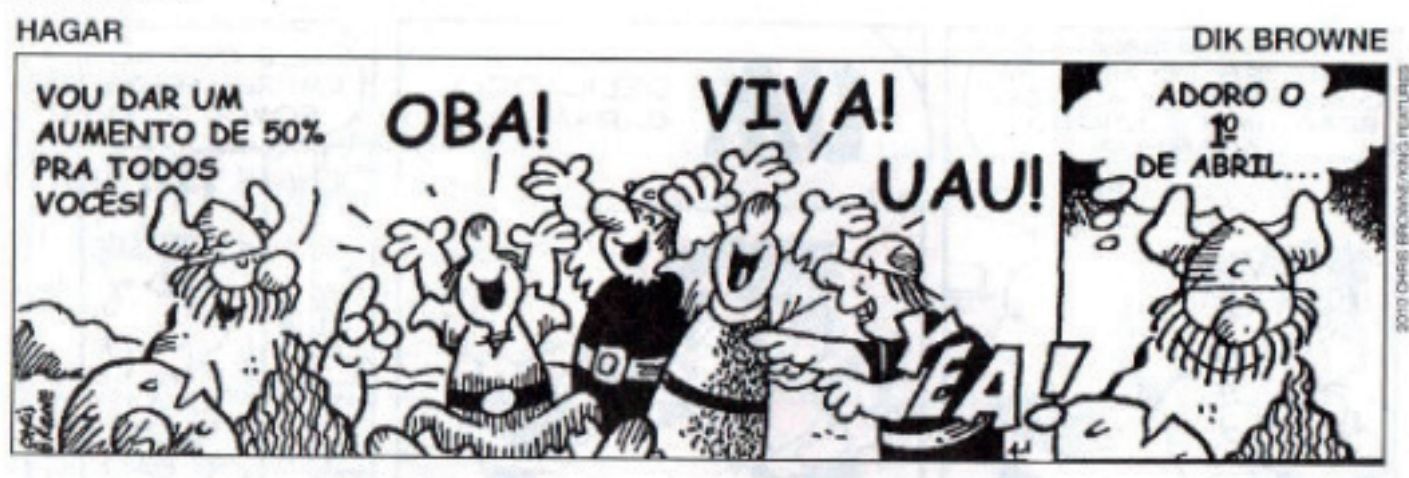

a) Transforme os números em palavras e classifique esses numerais.

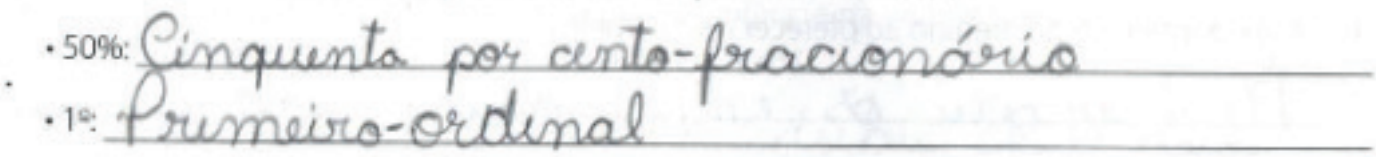

Fonte: ANJOS; PAMPLONA, 2016.

Podemos observar novamente o uso da nomenclatura "tira", assim como em um dos exemplos de Garfield, entretanto, o que chama a atenção é o papel que a tira ocupa nesse exercício. Ao analisarmos a letra A, fica claro que o real objetivo é fazer com que os alunos saibam diferenciar números cardinais, ordinais e fracionários. Se, no lugar dessa tira, o livro colocasse um texto com esses mesmos numerais, o real objetivo ainda seria alcançado. Portanto, é inegável que o uso desse gênero dos quadrinhos em grande parte dos materiais didáticos serve apenas para tornar os exercícios mais lúdicos.

O caso mais dúbio que observamos é o emprego da nomenclatura tira para nomear uma charge: 
Figura 6

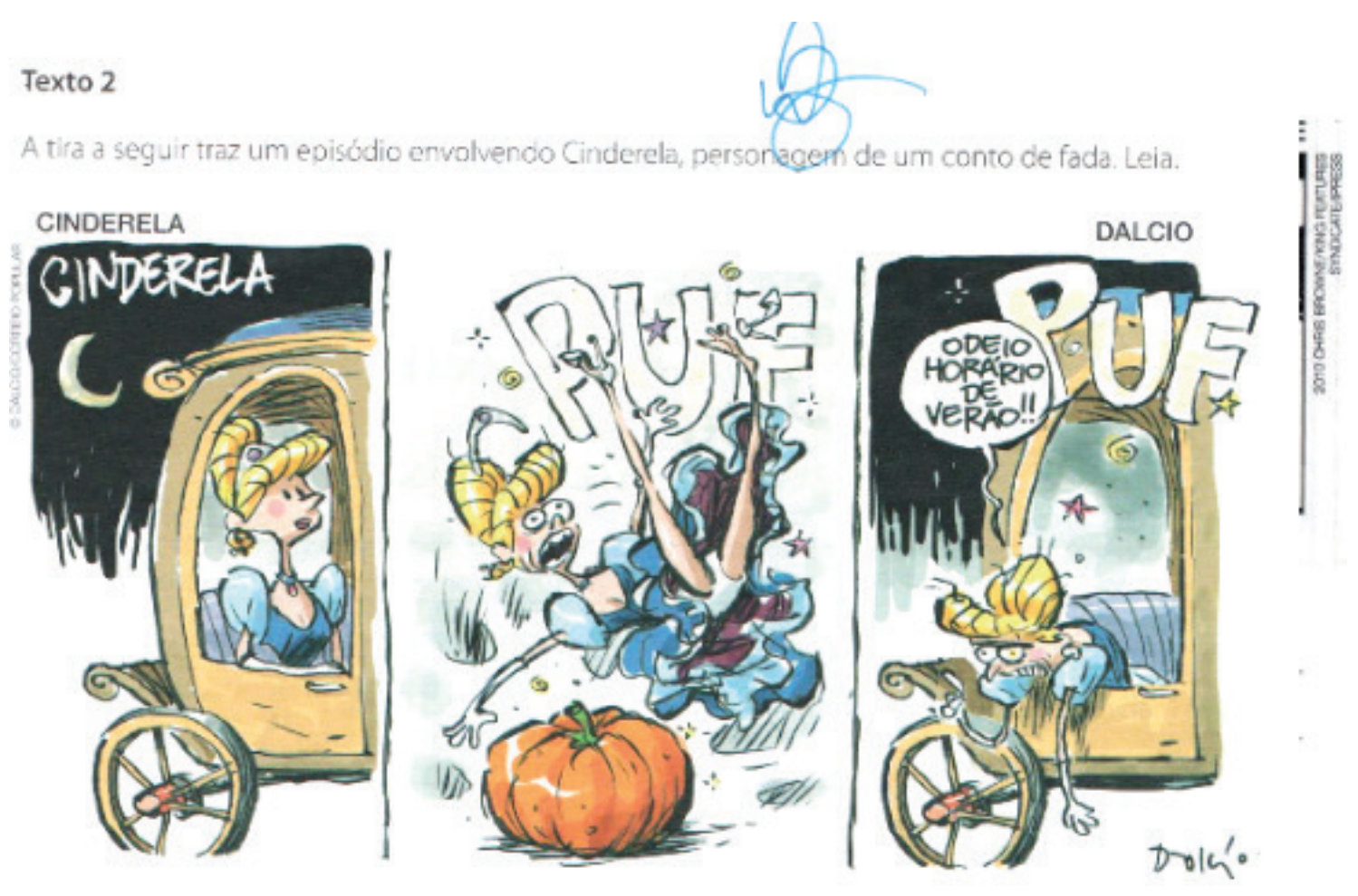

Fonte: ANJOS; PAMPLONA, 2016.

Para os conhecedores dos gêneros dos quadrinhos, após uma rápida olhada nos traços do desenho e no conteúdo da imagem acima, podemos constatar que se trata de uma charge. Contudo, a editora Uno baseada no conceito de que toda tira cômica tem formato horizontal, com três ou quatro quadros e com desfecho cômico, nomeou a produção acima como tira cômica apenas porque possui essas características. Segundo Romualdo (2000), "a charge é um texto de humor que aborda algum fato ou tema ligado ao noticiário. De certa forma, ela recria o fato de forma ficcional, estabelecendo com a notícia uma relação intertextual.”. Esta charge foi produzida pelo cartunista Dalcio Machado e veiculada pelo jornal Correio Popular de Campinas em 22 de fevereiro de 2015. Tendo como base essa definição de Romualdo, a época em que a charge foi veiculada faz toda a diferença para que possamos compreender o humor e afirmar que realmente se trata de uma charge. Tais dados foram eliminados pelo livro didático.

$\mathrm{Na}$ produção, temos a personagem Cinderela, conhecida mundialmente por ir a um baile com a ajuda de uma fada madrinha, responsável por transformar uma abóbora 
em carruagem, que voltaria a ser abóbora após a meia-noite. É exatamente disso que o cartunista faz o humor na charge, no último quadro quando a personagem diz: "odeio horário de verão". No mês de fevereiro, geralmente, é quando acaba o horário de verão, fato que interliga a charge com algo do cotidiano/atual da população como afirma Romualdo (2000). As pessoas atrasam o relógio em uma hora quando este marca meia noite e, assim, o mesmo horário se repete duas vezes. Por isso, a carruagem de Cinderela volta a ser abóbora (meia noite) no segundo quadro e novamente se transforma em carruagem (meianoite pela segunda vez após o ajuste do relógio) no terceiro quadro. Por estar ligado a um fato atual daquela época do ano (fim do horário de verão) e ser veiculado no jornal no mês de fevereiro, reforçam uma das características principais que diferem a charge da tira, já que a segunda não necessariamente precisa estar ligada a um fato do cotidiano das pessoas.

\section{ATIVIDADES PRÁTICAS}

A editora Uno dividiu seu material de Língua Portuguesa em gramática e produção de texto, cada tópico estudado em um bimestre de forma alternada. O que expusemos até o momento integra a parte de gramática do livro didático ( $1^{\circ}$ e $3^{\circ}$ bimestre). A partir deste momento, vamos abordar o material de produção de texto ( $2^{\circ}$ e $4^{\circ}$ bimestre), onde é proposto que os alunos coloquem em prática os conteúdos aprendidos na parte gramatical. Ao longo desta análise, é possível notar que as tiras cômicas foram usadas, em grande parte dos exercícios, como um mero recurso ilustrativo para aplicar conteúdos gramaticais. Assim, as principais características desse gênero foram pouco exploradas e, em alguns casos, uma visão superficial e errônea sobre formato das tiras foi passada aos alunos. Essas informações ambíguas são refletidas no momento de desenvolver as atividades de produção própria dos alunos. O exemplo a seguir é um dos primeiros do livro de produção de texto e disponibiliza um determinado formato para a produção que contradiz a definição já apresentada pelo livro didático: 
Figura 7

7 Leia este vecho do conto ${ }^{\circ} O$ indio" e crie uma tira narrando o episodia.

O porteiro abriu o portao - sem que ninguem entrasse - $e$ fitou ao longe o final da avenida; surgiu entre a poeina $e$ o derreter do asfalto um fusca, pneus baixos, rebaixado, parou em frente da escola, o ridio foi desligado, tal o silencio da multida que se ouviu o rangido da porta abrir, desceu um menino rolico, chicletes, bone do Chicago Bulls, tenis Reebok, calca jeass, camiseta, wallman nas orelhas, andou att o porteiro e perguntou:

- Pode assistir aula de walkman?

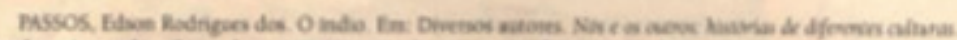

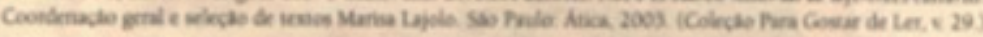

\section{Siga as instrucdes.}

1. Oivida a cena narrada em tres ou quatio quadros.

2. Desenhe-os em seu caderna. Você pode usar os quadros abalo como rascunho.

3. Utilize os baldes adequados eos recursos visuais apresentados nesta unidade.

4. Após a correça feita pelo professoc, faça a arte-final de swa tirinha utlizando canetas coloridas.

5. Organiae uma exposiço dos trabalhos com sua turma, no mural da sala de aula. Observe, nas tirinhas dos colegas, que elementos visuais foram usilzados e de que maneira foram organiza. dos os acontecimentos da historia.

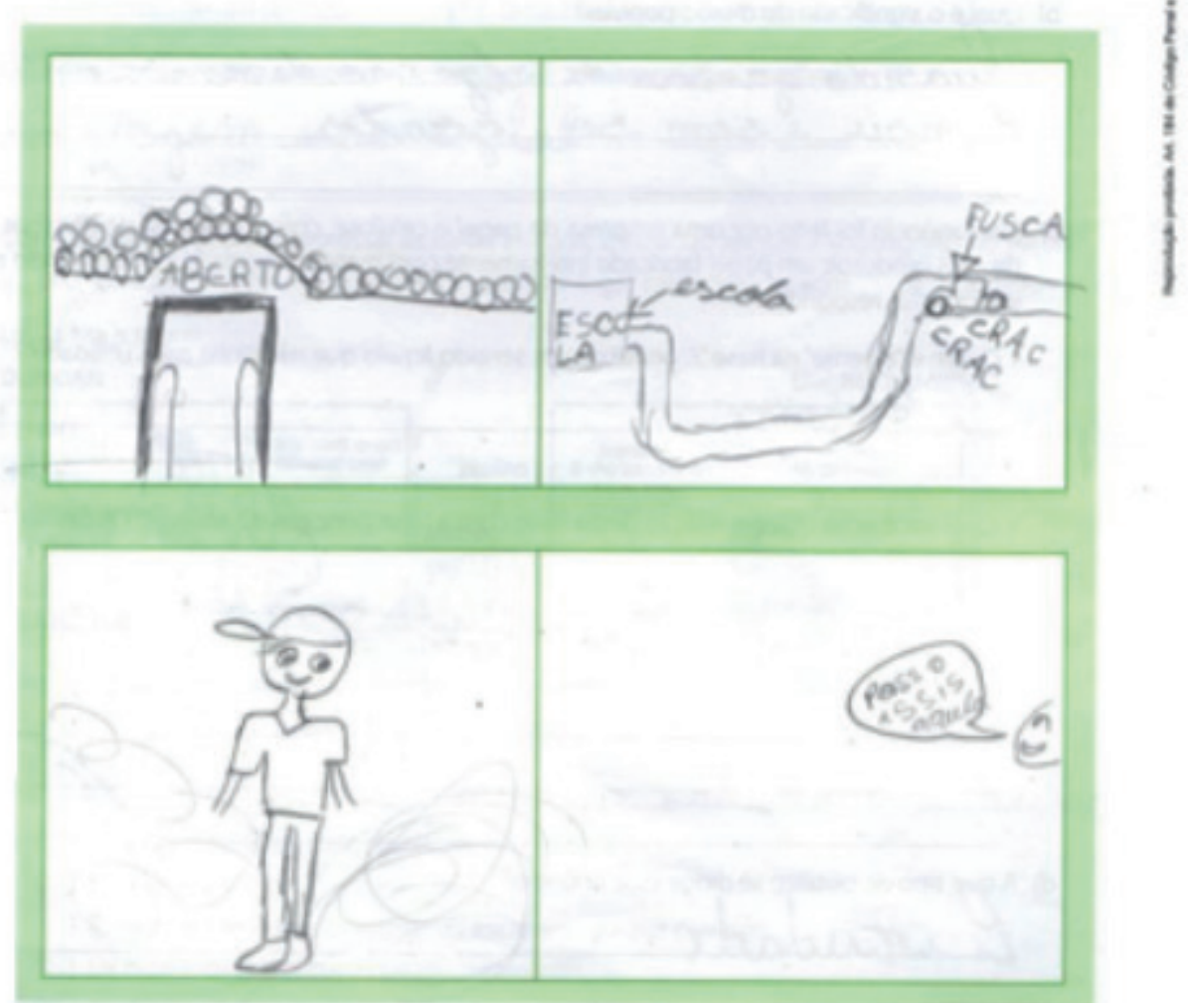

Fonte: ANJOS; PAMPLONA, 2016. 
Nesta atividade prática, de acordo com o enunciado, o aluno deveria narrar e ilustrar uma história em forma de tirinha (nomenclatura usada pelo enunciado). Em seguida, algumas instruções são dadas aos alunos, dentre elas, que esse espaço disponibilizado pelo livro deve ser usado como rascunho e, posteriormente, uma versão final da tirinha deve ser feita em outra página. Uma das possíveis implicações desse exercício prático é quanto ao formato. Durante a análise do livro de gramática, notamos que alguns exemplos contradizem o formato base que o material adota (horizontal, com três ou quatro quadros) e isso é constatado na produção final feita pela aluna B.D do $6^{\circ}$ ano B:

Figura 8

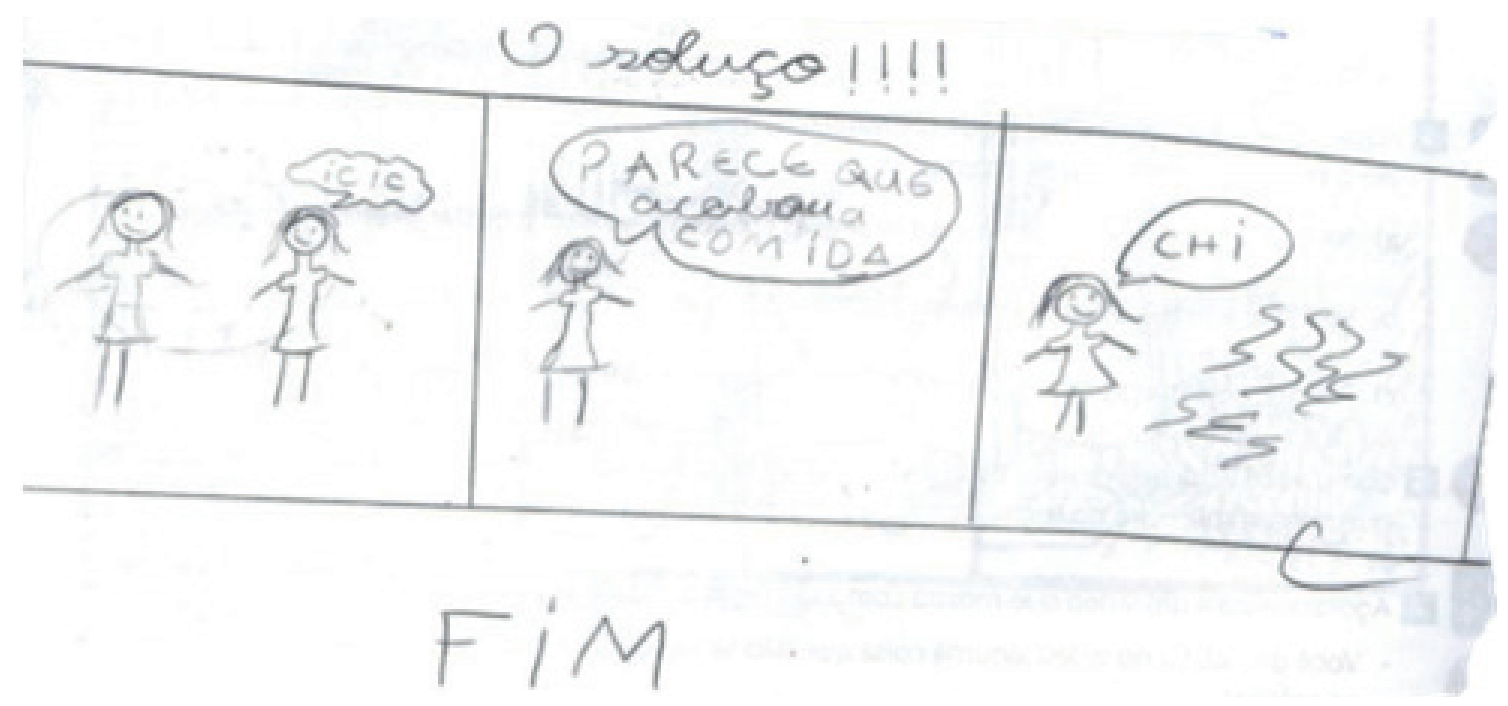

Fonte: ANJOS; PAMPLONA, 2016.

Em sua produção final, a aluna desenha a tirinha em um formato diferente do proposto no rascunho do livro didático. Podemos entender que, para ela, o formato de uma tirinha é o da figura 8 (espaço livre para a aluna criar) e, principalmente, observamos que o desfecho não é cômico, a palavra "fim" geralmente é usada no final de contos de fadas. Sendo assim, é possível constatar que as características do gênero tira cômica não se materializaram na produção e, ainda, na imagem observamos que a atividade foi corrigida pela professora que, provavelmente, também não foi bem instruída pelo material sobre como trabalhar esse gênero e suas principais características em sala de aula. 


\section{CONSIDERAÇÕES FINAIS}

Após a análise dos diferentes formatos que a tira cômica pode ter dependendo do suporte em que é veiculada e das diferentes nomenclaturas utilizadas pelo livro didático, concluímos que o gênero foi mal trabalhado tanto pelo livro didático quanto em sala de aula. Como dito anteriormente, na maioria das vezes o professor não é instruído em sua formação como trabalhar com o hipergênero dos quadrinhos e, assim, a responsabilidade de orientar professores e alunos sobre como trabalhar, identificar e produzir tiras cômicasfica a cargo do livro didático e, como analisamos nas atividades práticas, os exercícios exploraram pouco as características das tiras . Haveria outros caminhos que poderiam ser explorados. O primeiro seria que uma nomenclatura única fosse adotada - tira cômica -, mas que os diferentes formatos fossem expostos aos alunos para que, ao analisarem uma tira padronizada e outra não padronizada, e tivessem consciência de que as duas fossem tiras. A segunda proposta é que o livro tivesse um manual separado para o professor para orientar sobre as principais características das charges, HQs e tiras cômicas e, assim, instruir melhor seus alunos. A terceira diz respeito às atividades práticas que poderiam propor aos alunos a construção de tiras no formato tradicional e não tradicional e, além disso, atividades de criação livre, na qual eles utilizariam o formato que tivessem mais afinidade, mas, conscientes de que independentemente de qual escolhessem, estariam produzindo tiras cômicas. 


\section{REFERÊNCIAS:}

ANJOS, R.; PAMPLONA, R. Livro de Língua Portuguesa. São Paulo: Editora Uno, 2016.

BONINI, A. Mídia, suporte e hipergênero: os gêneros textuais e suas relações. Revista Brasileira de Linguística Aplicada. Belo Horizonte, v. 11, n. 3, p. 679-704, 2011.

RAMA, A.; VERGUEIRO, W. (Org.). Como usar as histórias em quadrinhos na sala de aula. São Paulo: Contexto,

RAMOS, P. Faces do humor: uma aproximação entre piadas e tiras. Campinas, SP: Zarabatana Books, 2011.

RAMOS, P. Tiras no ensino. São Paulo: Parábola Editorial, 2017.

RAMOS, P. Os formatos da tira no ensino. Revista Intersaberes, v. 12, n. 25, 2017, p.8497. Disponível em: <https://www.uninter.com/intersaberes/index.php/revista/article/ view/1210/665>. Acesso em: 5 jan. 2020.

RAMOS, P. Histórias em quadrinhos: gênero ou hipergênero? Revista de estudos linguísticos, São Paulo, p. 355-367, 2009.

ROMUALDO, E. C. Charge jornalística: intertextualidade e polifonia um estudo de charges da Folha de S. Paulo. Maring: Eduem, 2000.

VERGUEIRO, W. Panorama das histórias em quadrinhos no Brasil. São Paulo: Peirópolis, 2017.

VERGUEIRO, W.; SANTOS, R. E. Histórias em quadrinhos no processo de aprendizado: da teoria à prática. Revista Científica Eccos, São Paulo, n. 27, p. 81-95, 2012.

WATTERSON, B. Calvin e Haroldo: o livro do décimo aniversário. São Paulo: Conrad Editora do Brasil, 2013. 